\title{
Preliminary Exploration of the Mental Health Education Competency Survey of Primary and Middle School Head Teachers
}

\author{
Chunyu Liu ${ }^{1}$, Yanling Liu ${ }^{1}$, Cheng Guo ${ }^{1} \&$ Haiying $\operatorname{Lan}^{1}$ \\ ${ }^{1}$ Mental Health Education Research Center of Southwest University, Chongqing, China \\ Correspondence: Yanling Liu \& Cheng Guo, Mental Health Education Research Center, The Southwest \\ University, Chongqing, China.
}

Received: September 5, $2013 \quad$ Accepted: September 26, $2013 \quad$ Online Published: October 21, 2013
$\begin{aligned} & \text { doi:10.11114/jets.v2i1.215 } \\ & \text { URL: http://dx.doi.org/10.11114/jets.v2i1.215 }\end{aligned}$

\begin{abstract}
Despite a recent focus on the mental health of students, primary and middle school mental health education in China has been hampered by a lack of resources fand inadequate professional training. This study assessed the mental health education competency of primary and middle school head teachers using the Mental Health Education Competency Questionnaire, a measure based on data from documentary analysis, behavioral event interviews (BEIs), and expert judgment. Factor, reliability, and validity analysis of this questionnaire were conducted. Through these analyses, seven structural dimensions of mental health education competency were found: mental health education skill, career growth, personality charm, occupational tendency, achievement feature, student perspective, and professional knowledge. This questionnaire will improve hiring and evaluation processes and, therefore, improve mental health education.
\end{abstract}

Keywords: primary and middle school head teacher, mental health education, competency, competency model

\section{Introduction}

Due to increasing concerns about the mental health of students, mental health education programs have improved (Graham, Phelps, Maddison, \& Fitzgerald, 2011). However, the development of primary and middle school mental health education in China has been restricted due to a lack of resources and inadequate professional training (Wang \& Zhang, 2011). In the The Outline of Education Guide for Pupil's Mental Health published by the Ministry of Education (2002), the head teacher is appointed the administrator of mental health education in primary and middle schools and the major resource for teacher resources. Mental health education, a multi-displinary curriculum that involves psychology, pedagogy, and sociology, can be professional, practical, and operational. These features require a high standard of efficiency and knowledge from a head teacher.

Many foreign researchers, including Bisschoff and Grobler (1998), have studied our teacher competency. In China, relevant research primarily focuses on the competency of the headmaster, disciplinary teacher, mental health teacher, and college counselor (Zeng, 2007; Jie, Ma, Zhou \& Chen, 2009; Sun \& Yang, 2012; Xu, Tan, Wu, Yang, \& Tan, 2011), and frequently neglects the head teacher. Currently, many provinces conduct mental health education training for primary and middle school teachers (e.g., Heilongjiang, Shandong, and Chengdu). Teacher accreditation is offered in three levels (A, B, and C). However, these training sessions cannot solve the practical problems of psychological guidance because of their theory-oriented character and lack of relevance, as well as the lack of a clear requirement about competency standards. The study of primary and middle school head teachers' competency should be accelerated to change the current situation.

The definition of competency has been disputed since it was first raised. Among the many definitions, those of McClenand, Boyatizis and Spencer are widely recognized. McClelland (1973) defines competence as a "deep characteristic that can distinguish the superior from the ordinary in work, including different motivation performance, personality traits, morals, self-image, social role character, attitude or value and the knowledge or skill in certain field." Boyatzis and Royatzis (1982) pointed out that competency is an individual trait that encompasses motivation, personality, skill, self-image, social role, and the body of knowledge, and Spencer (1993) suggested that competency is a trait that can separate the outstanding from the mediocre in work, organization, or culture. Competency can include motivation, personality, self-image, attitudes, values, or an 
intellectual, cognitive, or behavioral skill in some domain. Although definitions vary, there is agreement that the following three requirements in a definition of competency.

1) Competency is closely related to job performance.

2) Competency is confined to specific job duties and positions, and depends on personal traits, such as motivation, personality, skills, knowledge, attitudes, or values.

3) Competency is capable of distinguishing between outstanding and poor performance.

Competency has gradually been recognized as a lasting characteristic, and, among its features, more attention has been paid to social aspects, such as values and self-image (Shippmann et al., 2006). A definition of competency must take into account previous studies, China's cultural background, the target, objectives and content of mental health education, and the responsibilities and functions of a head teacher. The relevant knowledge, skills, abilities, character, emotive motivation, career ideology, and awareness are necessary for a primary and middle school head teacher to be competent in mental health education in a variety of teaching situations.

This research adopts scientific competency modeling methods to establish a mental health education competency questionnaire for head teachers in primary and middle schools. The purpose of this questionnaire is to provide information for the head teacher selection process, performance evaluations, and post-job reviews of primary and middle school head teachers. This will drive the improvement of mental health education and enrich the body of literature and theory about competency.

\section{Method}

\subsection{Participants and Procedure}

\subsubsection{Behavioral Event Interview (BEI) Phase}

In Chongqing, 24 primary and middle school head teachers were selected for the BEI. This total included 14 high-performing head teachers (10 years of working experience as head teachers, five years of mental health education experience, recommendations of school leaders, and recognition for achievement with honors higher than district or county level). Of these 14 head teachers, four were selected as pre-research targets and ten were selected to form the "high-performance" team. The additional ten head teachers that were not designed high-performance formed the "normal" team.

\subsubsection{Primary Survey Phase}

Two hundred questionnaires were distributed through e-mails or in person to schools in various cities, including Chongqing, Sichuan, and Guangdong, and 161 were returned (80.5\%). After excluding 18 invalid questionnaires, the remaining 143 (88.8\% of the returned questionnaires) were used in the analysis.

\subsubsection{Formal Survey Phase}

Three hundred and fifty questionnaires were distributed, and 306 (87\%) were returned. After excluding 43 invalid questionnaires, the remaining 263 ( $86 \%$ of the returned questionnaires) were used in the analysis (see Table 1).

Table 1. Distribution Table of Testees Participated in Formal Survey ( $\mathrm{N}=263)$

\begin{tabular}{crrr}
\hline Grouping Variable & Category & Number & Percentage \% \\
\hline Gender & Male & 63 & 24.0 \\
& Female & 200 & 76.0 \\
Serve in & Primary school & 133 & 50.6 \\
& Middle school & 100 & 38.0 \\
Age & High school & 30 & 11.4 \\
& $20-30$ & 111 & 42.2 \\
& $31-40$ & 89 & 33.8 \\
& $41-50$ & 50 & 19.0 \\
Job Duration as & Over 51 & 13 & 4.9 \\
head teacher & 1 year & 32 & 12.2 \\
& $2-3$ years & 49 & 18.6 \\
& $4-6$ years & 50 & 19.0 \\
& $7-10$ years & 44 & 16.7 \\
Participation in & Over 10 years & 88 & 33.5 \\
relevant mental & Yes & 236 & 89.7 \\
health trainings & No & 27 & 10.3 \\
Acquisition of & Yes & 104 & 39.5 \\
outstanding head teacher & No & 159 & 60.5 \\
\hline
\end{tabular}




\subsection{Measures}

Three measures were developed for use in this study. The outline for the BEI about mental health education competency was developed first, followed by the first version of a questionnaire on the same topic. Finally, a formal version of the questionnaire was developed. Please see the Process section below for more details.

\subsection{Process}

\subsubsection{Document Analysis}

The purpose of the document analysis was to develop theoretical dimensions of primary and middle school head teachers' mental health education.

Ninety-two research reports that were relevant to primary and middle school head teachers' mental health education competency were reviewed. The models and definitions of competency from these papers were collected, from which five first-class indicators and 12 second-class dimensions were selected.

1) Knowledge and Skill (two dimensions): professional knowledge and specific skill.

2) Ability (three dimensions): psychological guidance skills, interpersonal communicating skills, and data collecting, and processing ability.

3) Personality (two dimensions): personal charm and self-concept.

4) Emotive motivation (two dimensions): achievement traits and emotionality.

5) Career, Ideology and Awareness (three dimensions): student perspective, occupational tendency, and career growth

A competency vocabulary ( 85 words) was selected by a search of competency related documents and the analysis of descriptive definitions and dimension standards.

\subsubsection{Evaluation of BEI Results}

The purpose of the BEI was to identify the dimensions and vocabulary related to competency and to verify the selected theoretical dimensions

The process of collecting and analyzing information was developed based on the work of Spencer (1993). First, we conducted and recorded interviews using the BEI. The dimensions of competency-related words and sentences were selected after computer and human analyses, and the results were compared across the high-performance and the normal teams.

Eight dimensions were found to be significantly different between the high-performing and normal teams: professional knowledge, psychological guidance skill, personality charm, self-concept, accomplishment trait, emotionality, student perspective, occupational tendency, and career growth. Two other dimensions (interpersonal communicative ability and information collecting and processing ability) were less distinctive. The competency vocabulary was reviewed and adjusted to 50 words.

\subsubsection{Expert Judgment}

A panel of experts in mental health education and outstanding teachers was formed to review the competency dimensions and vocabulary compiled from the previous studies. After careful discussion and consideration, the eight dimensions and 50 vocabulary words were approved. These 50 words transformed into behavior descriptive sentences For example, "educational and teaching experience" was described as "having mental health education experience" and "being considerate" was changed to "able to think from students' perspective and understand their feelings."

The Primary Mental Health Competency Questionnaire for Middle School Head Teachers (consisting of 64 behavior descriptive sentences) was compiled. This questionnaire adopted a 5 -point Likert scale ( $1=$ "extremely unimportant" to 5 = "extremely important"). Thus, the questionnaire requires primary and middle school head teachers to judge the importance of the 64 behavior descriptive sentences based on their own work experience.

\subsubsection{Predication}

To examine and refine the primary questionnaire, we analyzed the results of 143 completed questionnaires (see section 2.1.2 for details).

Any item with a correlation with the total points of the questionnaire less than 0.3 was eliminated, and items with a correlation with each other of more than 0.8 were combined. Through primary factor analysis, items with less than 0.4 factor loading and poor differentiation were eliminated, and repeated explorations were conducted until 
the accumulative variance rate became steady. According to the analysis of responses to the primary questionnaire, and based on mental health education experts' advice, we revised the questionnaire and adjusted several dimension names (e.g. changed the phrase "professional knowledge" to "knowledge and experience"). Some descriptions were modified to improve the structure of the questionnaire. The final questionnaire contains 42 items and retains the 5-point Likert scale.Statistic analysis software, SPSS 16.0 for Windows, was used to analyze the collected data.

\section{Results}

\subsection{Exploration of the Structural Dimension of Primary and Middle School Head Teachers' Mental Health} Education Competency

According to the analysis of responses, the Kaiser-Meyer-Olkin had a value of 0.875 (approximate to 1). The value of X2, based on Bartlett's sphericity test, was 3,624.08 ( $\mathrm{df}=703, p<.001)$. Because this test was significant, we preceded with factor analysis. During factor analysis, we adopted principal component analysis to extract factors and Promax oblique rotation as the rotating method. The extracting standard was set as eigenvalue larger than 1, with unlimited factor extraction. As the results show (Table 2 and Table 3), the structure of this questionnaire is stable and its items are intensive. Three items, "establish good relationship with students," "positive initiative," and "respect for students," were deleted from the rest of the analysis.

Table 2. Rotation Factor Eigenvalue and Contribution Rate for Primary and Middle School Head Teachers' Mental Health Education Competency Factors

\begin{tabular}{cccc}
\hline Factor & Eigenvalue & Variance Percentage (\%) & Accumulative Variance Percentage (\%) \\
\hline mental health education skill & 7.107 & 18.702 & 18.702 \\
career growth & 4.480 & 11.789 & 30.492 \\
personality charm & 3.839 & 10.102 & 40.594 \\
occupational tendency & 3.342 & 8.795 & 49.389 \\
achievement feature & 2.494 & 6.564 & 55.953 \\
student perspective & 2.380 & 6.262 & 62.215 \\
professional knowledge & 1.539 & 4.050 & 66.265 \\
\hline
\end{tabular}

Table 3. Loading Matrix of Primary and Middle School Head Teachers' Mental Health Education Competency Scale

\begin{tabular}{|c|c|c|c|c|c|c|c|c|}
\hline No. & $\begin{array}{l}\text { mental } \\
\text { health } \\
\text { education } \\
\text { skill }\end{array}$ & $\begin{array}{l}\text { career } \\
\text { growth }\end{array}$ & $\begin{array}{l}\text { personality } \\
\text { charm }\end{array}$ & $\begin{array}{c}\text { occupational } \\
\text { tendency }\end{array}$ & $\begin{array}{l}\text { achievement } \\
\text { feature }\end{array}$ & $\begin{array}{c}\text { student } \\
\text { perspective }\end{array}$ & $\begin{array}{l}\text { professional } \\
\text { knowledge }\end{array}$ & Communalities \\
\hline A50 & 0.801 & & & & & & & 0.732 \\
\hline A26 & 0.800 & & & & & & & 0.696 \\
\hline $\mathrm{A} 40$ & 0.712 & & & & & & & 0.681 \\
\hline $\mathrm{A} 27$ & 0.702 & & & & & & & 0.730 \\
\hline A41 & 0.676 & & & & & & & 0.613 \\
\hline A39 & 0.672 & & & & & & & 0.635 \\
\hline A 38 & 0.666 & & & & & & & 0.602 \\
\hline A49 & 0.656 & & & & & & & 0.591 \\
\hline A56 & 0.622 & & & & & & & 0.616 \\
\hline A47 & 0.562 & & & & & & & 0.640 \\
\hline B12 & & 0.796 & & & & & & 0.696 \\
\hline B24 & & 0.712 & & & & & & 0.685 \\
\hline B13 & & 0.704 & & & & & & 0.694 \\
\hline B36 & & 0.604 & & & & & & 0.676 \\
\hline B53 & & 0.587 & & & & & & 0.604 \\
\hline B19 & & 0.572 & & & & & & 0.582 \\
\hline B25 & & 0.525 & & & & & & 0.585 \\
\hline B43 & & 0.512 & & & & & & 0.590 \\
\hline B54 & & 0.487 & & & & & & 0.649 \\
\hline $\mathrm{C} 55$ & & & 0.693 & & & & & 0.690 \\
\hline
\end{tabular}




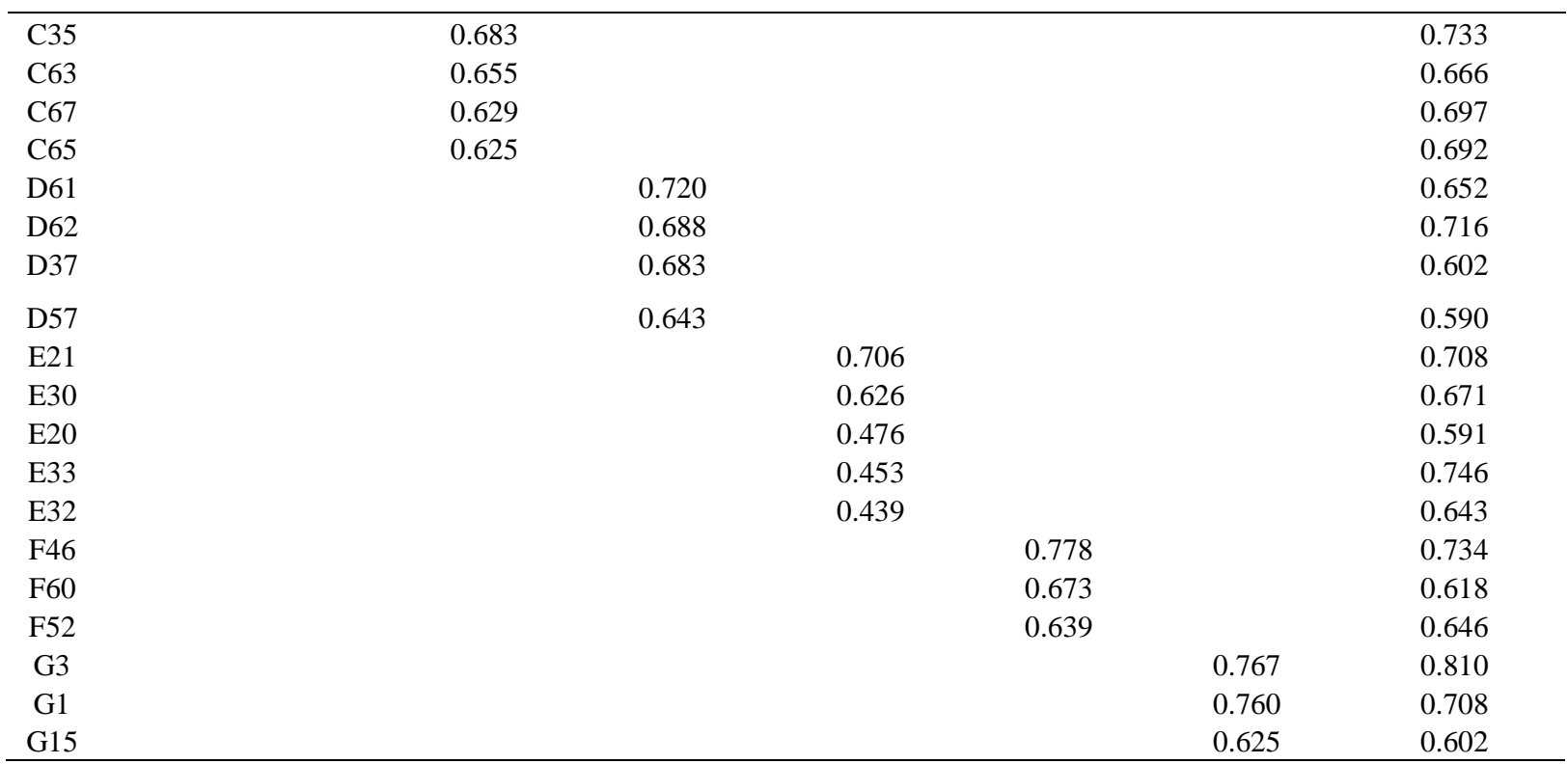

We selected seven factors, which explained $66.265 \%$ of the total variance; this implies strong interpretability of each factor. Among all the items loading, the highest was 0.801 and the lowest was 0.439 , and item communalities varied between 0.582 and 0.810 . The seven selected factors were mental health education skill, career growth, personality charm, occupational tendency, achievement feature, student perspective, and professional knowledge.

\subsection{Questionnaire Reliability}

The $\alpha$ coefficient was used to test reliability (Table 4). The $\alpha$ coefficient of each factor varied from 0.714 to 0.928 , indicating satisfactory reliability. The $\alpha$ coefficient of the total scale had value of 0.957 , which indicates good internal consistency.

Table 4. Reliability Evaluation of Primary and Middle School Head Teachers' Mental Health Education Competency Scale

\begin{tabular}{cc}
\hline & Internal consistency reliability coefficient $(\alpha)$ \\
\hline Mental Health Education Skill & 0.928 \\
Career Growth & 0.887 \\
Personality Charm & 0.795 \\
Occupational Tendency & 0.865 \\
Achievement Feature & 0.779 \\
Student Perspective & 0.726 \\
Professional Knowledge & 0.714 \\
Total Scale & 0.957 \\
\hline
\end{tabular}

\subsection{Questionnaire Validity}

Due to a lack of existing mental health education competency scales for primary and middle school head teachers, this research did not test criterion validity.

\subsubsection{Construct Validity}

This research estimates construct validity by referring to the relevance between each factor, and between each factor and the total score. Generally, a medium or low relevance between each factor of a scaled questionnaire is acceptable (Table 5). The relevance between each factor was $0.309-0.716$, and mostly between 0.4-0.6, indicating a medium degree of relevance. The relevance between factors and the total score was $0.565-0.879$, which is comparatively high. Relevance between each subscale was lower than that between the subscale and the total score, representing good construct validity. 
Table 5. Construct Validity of Primary and Middle School Head Teachers' Mental Health Education Competency Scale

\begin{tabular}{|c|c|c|c|c|c|c|c|c|}
\hline Dimension & 1 & 2 & 3 & 4 & 5 & 6 & 7 & 8 \\
\hline 1.Mental Health Education Skill & 1.000 & & & & & & & $0.879^{* *}$ \\
\hline 2.Career Growth & $0.609^{* *}$ & 1.000 & & & & & & $0.840^{* *}$ \\
\hline 3.Personality Charm & $0.570^{* *}$ & $0.589^{* *}$ & 1.000 & & & & & $0.787^{* *}$ \\
\hline 4.Occupational Tendency & $0.712^{* *}$ & $0.625^{* *}$ & $0.600^{* *}$ & 1.000 & & & & $0.827^{* *}$ \\
\hline 5.Student Perspective & $0.694^{* *}$ & $0.716^{* *}$ & $0.677^{* *}$ & $0.637^{* *}$ & 1.000 & & & $0.849^{* *}$ \\
\hline 6.Achievement Feature & $0.521^{* *}$ & $0.444^{* *}$ & $0.592^{* *}$ & $0.503^{* *}$ & $0.509^{* *}$ & 1.000 & & $0.674^{* * *}$ \\
\hline 7.Professional Knowledge & $0.428^{* *}$ & $0.314^{* *}$ & $0.345^{* *}$ & $0.309^{* *}$ & $0.312^{* *}$ & $0.343^{* *}$ & 1.000 & $0.565^{* *}$ \\
\hline 8.Total Score & $0.879^{* *}$ & $0.840^{* *}$ & $0.787^{* *}$ & $0.827^{* *}$ & $0.849^{* *}$ & $0.674^{* *}$ & $0.565^{* *}$ & 1.000 \\
\hline
\end{tabular}

Note: $* p<0.05 ; * * p<0.01$;

\subsubsection{Content Validity}

Content validity examines the match between the degree of measured content and the ideal content. Scale content validity determines to what degree the scale represents the behavioral domain. During the compilation of this questionnaire, scale design principles were strictly followed. The basic structure of the scale and items were determined in accordance to document analysis, BEI, and expert judgment, and the final theoretical structure and items were established after repeated analysis, discussion, the primary survey, and revisions. All these measures ensure the content validity of the questionnaire.

\section{Discussion}

\subsection{Structural Features of Primary and Middle School Head Teachers' Mental Health Education Competency}

This research adopts an integrated research approach, which combines theory and demonstration. First, the theoretical dimensions of primary and middle school head teachers' mental health education competency was developed through document analysis, then the theoretical dimensions were checked and revised by practical interviews, experts and use of the primary questionnaire. Finally, the structure was completed, resulting in seven dimensions (mental health education skill, career growth, personal charm, occupational tendency, achievement feature, student perspective, and professional knowledge).

The ability index, which existed in the theoretical structure document analysis, was omitted from the final scale. Psychological guidance ability was combined with the knowledge and skill index and was renamed, together with professional skill, mental health education skills. Information collecting and processing ability as well as communication skills were integrated into the mental health education skill dimension, with several items being retained. Psychological guidance itself is an important type of interpersonal communication (Bibou,Nakou \& Kiosseoglou, 2000), and it is not surprising that interpersonal skills are deemed essential to mental health education competency.

\subsection{Head teacher and Mental Health Teacher Competency}

The established mental health education competency survey of primary and middle school head teachers contains seven dimensions.

After comparing the competency of primary and middle school head teachers studied in this paper with the competency of professional mental health teachers studied by foreign and other Chinese scholars (Baker, Robichaud, Westforth Dietrich, Wells, \& Schreck, 2009; Trusty \& Brown, 2005; Zeng, 2007; Chen, 2007), we found similarities in following fields: personality charm, emotionality and occupational tendency. However, the competency of head teachers is difficult to rate. For example, in a professional field of knowledge, judging the competency of a primary or middle school head teacher should focus on psychological guidance skills and interpersonal ability, but for a professional mental health teacher, the focus should be placed on heady capacity. This need to adjust focus may be caused by the wide scope of responsibilities of primary and middle school head teachers.

\subsection{General Competency and Mental Health Education Competency}

Though similar in some aspects, including the emphasis on knowledge, career ideology, and intention, this research differs from general competency studies of primary and middle school head teachers made by the domestic scholar Han and Yang (2006). The knowledge structure emphasized in mental health education competency includes psychological knowledge and how to apply such knowledge to organize activities, as well 
as how to understand the psychology of the students (House \& Hayes, 2002), while the knowledge structure of a head teachers' general competency tends to focus more on disciplinary knowledge and other relevant skills. General competency stresses professional ethics (Li \& Huang, 2011), but mental health education competency requires professional ideology and career growth. Generally speaking, the head teacher is a mentor of children; thus, professional ethics need to be in place, but for mental health education, relevant training and knowledge are more important, thus professional ideology and career growth get more attention in this field.

In summary, the orientation and methods of this research contributes to the construction of a rational, subjective, and interpretable competency model.

\section{Conclusions}

The structure of primary and middle school head teachers' Mental Health Education Competency Scale includes seven dimensions. This competency scale has satisfactory internal consistency, construct validity, and content validity.

\section{Limits and Future Directions}

As a new research tool, the mental health education competency of head teachers still needs revision and reconsideration.

The role of primary and middle school head teachers is quite difficult. Faced with a myriad of responsibilities, many head teachers, especially in middle schools, had little time to participate in this study, which prevented us from obtaining a better sample; selecting participants from different grades or a more evenly gender balanced sample would be useful. Due to limited time and research funds, the sample could only be drawn from several provinces, such as Chongqing and Sichuan, leading to a possible geographical disparity, and thus hindering the generalization of results.

At present, research about the mental health education competency of primary and middle school head teachers is just beginning. The conceptions, structural dimensions, and testing methods are still being examined. In future studies, participants should be selected for more appropriate distributions in grades and gender. In addition, more cities should be surveyed, such as Chongqing or cities in the east. A more practical competency model could be built by comparing and analyzing a variety of proposed competency structures. Also, with consistent testing, research, and exploration, a more scientific, reliable, and standardized primary and middle school head teachers' mental health education competency scale can be developed. Issues relevant to competency, such as job burnout, job performance, and job satisfaction, should also be examined to increase the practical significance of the competency.

\section{Acknowledgements}

This study was supported by the fund of research center of mental health education of Southwest University ,the key reserch base of the humanities and social science research of Chongqing, China

\section{References}

Baker, S. B., Robichaud, T. A., Westforth Dietrich, V. C., Wells, S. C., \& Schreck, R. E. (2009). School counselor consultation: A pathway to advocacy, collaboration, and leadership. Professional School Counseling, 12(3), 200-206.

Bibou - Nakou, I., \& Kiosseoglou, G. (2000). Factorary teachers' perceptions regarding school behavior problems: Implications for school psychological services. Psychology In The Schools, 37(2), 123-134.

Bisschoff, T., \& Grobler, B. (1998). The management of teacher competence. Journal of In-service Education, 24(2), 191-211. http://dx.doi.org/10.1080/13674589800200041

Boyatzis, R. E., \& Royatzis, R. (1982). The competent manager: A model for effective performance: Wiley New York.

Chen ,H. (2007). Research on the Competency of Teachers for School Mental Health Education. Fuzhou: Fujian Normal University.11-12. http://dx.doi.org/10.7666/d.y1184345

Graham, A., Phelps, R., Maddison, C., \& Fitzgerald, R. (2011). Supporting children's mental health in schools: teacher views. Teachers and Teaching, 17(4), 479-496. http://dx.doi.org/10.1080/13540602.2011.580525

House, R. M., \& Hayes, R. L. (2002). School Counselors: Becoming Key Players in School Reform. Professional School Counseling, 5(4), 249-256.

Han, M. R., \& Yang, J. P. (2006). Research of Competence of Middle- School Head Teacher. Theory and 
Practice of Education, 26(1), 59-61.

Jie ,S.P., Ma, H.Y., Zhou, Z.K., \& Chen, J.W. (2009). A Research on Quality Structure of Excellent Directors of Class in the Primary School, Journal of Southwest University(Social Sciences Edition), 35(2), 139-142. http://dx.doi.org/10.3969/j.issn.1673-9841.2009.02.025

Li ,M., \& Huang, Z.J. (2011). Exploration to the Competency of Primary and Middle School Headteacher. Ideological \& Theoretical Education, 20, 28-32. http://dx.doi.org/10.3969/j.issn.1007-192X-B.2011.10.009

McClelland, D. C. (1973). Testing for competence rather than for" intelligence.". American Psychologist, 28(1), 1. http://dx.doi.org/10.1037/h0034092

Ministry of Education of the People's Republic of China. (2002). The Outline of Education Guide for Pupil's Mental Health. People's Education Press.

Shippmann, J. S., Ash, R. A., Batjtsta, M., Carr, L., Eyde, L. D., Hesketh, B., Sanchez, J. I. (2006). The practice of competency modeling. Personnel Psychology, $503-740$. http://dx.doi.org/10.1111/j.1744-2000.tb00220.x

Spencer, M. (1993). Competence at Work Models for Superior Performance. New York. NY: Viking Press.

Sun, Y.G., \& Yang ,W.J. (2012). The Study on the Competency Model of Head Teachers in Primary School. Education Science, 6, 79-82. http://dx.doi.org/10.3969/j.issn.1002-8064.2011.06.017

Trusty, J., \& Brown, D. (2005). Advocacy competencies for professional school counselors. Professional School Counseling, 8(3), 259-265.

Wang, Z., \& Zhang, D.J. (2011). Measurement of Competencies of Mental Health Teachers. Journal of Psychological Science, 34(2), 481-487.

Wei ,X.Y., Wang ,Y., \& Guo, C.(2012). Research Review of Primary and Middle School Headteacher's Mental Health Education Competency. Journal of Higher Correspondence Education(Philosophy and Social Sciences), 11, 29-31. http://dx.doi.org/10.3969/j.issn.1007-2187.2011.11.010

Xu, J. P., Tan, X. Y., Wu, L., Yang, M., \& Tan, S. G. (2011). Analysis of Competencies of Excellent Teachers in Primary and Secondary Schools. Journal of Educational Studies, 001, 48-53.

Zeng, L. J. (2007). A Primary Study of the Cultivating Competency of Mental Health Education Teachers. Psychological Science, 30(4), 977-978. http://dx.doi:10.3969/j.issn.1671-6981.2007.04.053

\section{$(\mathrm{cc}) \mathrm{BY}$}

This work is licensed under a Creative Commons Attribution 3.0 License. 